\title{
Observaçōes sobre o comportamento de acasalamento de Culex quinquefasciatus Say (Diptera-Culicidae)
}

\author{
J. Derek Charlwood (")
}

\begin{abstract}
Resumo
Um estudo foi conduzido sobre o comportamento de acasalamento de linhagens de Culex quinquefasciatus Say do Gâmbia, África Ocidental e Amazonas, Brasil. Usando um sistema de telcvisāo sensivel ao infravermelho para observação no "escuro", os experimentos mostraram que os machos são atraídos pela emissāo de som no vôo da fêmea e pareceram não distinguir entre membros de suas espécies e de outros gêneros. A resposta dos machos à emissão de som artificial de vôo da fêmea tem um pico em L.D. 12:12 na hora se. guinte à interrupção da luz no laboratório e apresenta um padrão circadiano em escuro constante. No campo, o acasalamento foi observado quando os machos estavam em enxame voando ativamente. A conclusão obtida é de que o acasalamento depende da atividade do macho, mas que a escolha do padrão específico da es. pécie depende da fêmea.
\end{abstract}

\section{INTRODUÇÃo}

Apesar de sua importância como vetor de doenças, pouco se sabe sobre o comportamento de acasalamento de Culex quinquefasciatus Say. Uma vez que o bem sucedido uso da técnica de esterilizar o macho como meio de controle depende de que tais machos possam competir favoravelmente com machos normais, está se tornando altamente importante conhecer os fatores que influenciam o acasa. lamento nesta espécie.

Pontos conflitantes existem sobre a função do enxame e do acasalamento nesta espécie. Assim, Sebastian \& DeMeillon (1967) pensaram que o enxame não estava necessariamente relacionado com o acasalamento, uma vez que eles observaram, em laboratório, c acasalamento atingindo um pico após meia noite, quando o uso em grupo dos machos já havia cessado há longo tempo. Williams \& Patterson (1969) por outro lado, concluíram que o acasalamento depende do vôo dos ma- chos em grupo. Se o acasalamento é independente do uso em grupo então a escolha de um padrão específico da espécie dependeria mais provavelmente do macho, como ocorre em espécies que não voam em grupo como Aedes aegypti (L) (Nijhout \& Craig), Deinocerites cancer (Provost \& Haeger, 1967) e Sabethes chloropterus (Galindo, 1958). Se o acasalamento está associado com o vôo em grupo, então a escolha do padrão pode depender da fêmea voar para dentro de um vôo em grupo de machos. Tais machos são capazes de perceber o tom do vôo da fêmea com a ajuda de suas antenas plumosas (Roth, 1949; Clements, 1963; Charlwood, 1976) e tentam acasalar-se com qualquer inseto que tenha um tom de vôo semelhante ao da fêmea, como faz c macho de vôo em grupo de Anopheles gambiae s/ (Charlwood \& Jones, 1979). Assim, uma resposta dos machos a sons que imitam o tom de vôo fornece uma estimativa precisa da tendência para acasalamento dos insetos.

Conseqüentemente um estudo foi efetuado para determinar se machos de $C$. quinquefasciatus são mais suscetiveis às fêmeas durante o período quando eles estariam voando em grupo e considerar que fatores, se há algum, influenciam a escolha de padrão dos machos.

\section{MÉTodos}

Cultivos de $C$. quinquefasciatus originários de Keneba, Gâmbia, África Ocidental e Manaus, Amazonas Brasil, foram usados nos experimentos. Larvas alimentadas com uma suspensão de pó de fígado, foram criadas em um insectário mantido a $26 \pm 2^{\circ} \mathrm{C}$ em um LD 1212 regime de luz. Adultos foram sexados $\epsilon$ separados - em emersão e foram usados

(*) - Instituto Nacional de Pesquisas da Amezônia, Manaus. 
nos experimentos quando com três ou quatro cias de idade. As observações no "escuro" foram efetuadas com o auxílio de uma câme. ra de televisão sensivel ao infravermelho Link IOI (Charlwood, 1974 e 1976; Charlwood \& Jones, 1979) em um insectário mantido nas mesmas condições do insectário de criação. Infravermelho foi fornecido por uma lâmpada de 15 watts em um segurador Ilford "Safelight" coberto por um filtro infravermelho Kodak Watten $88 \mathrm{~A}(10 \%$ de emissão a $740 \mathrm{~nm}, 0.1 \%$ a $720 \mathrm{~nm}$ ). A imagem da câmera foi transmitida para um "vídeo tape recorder" situado fora do laboratório e mostrado em um monitor preto e branco.

Durante os experimentos, que foram efetuados em gaiolas padrão cobertas com musselina com $300 \mathrm{~mm}$ de lado, a fonte de infravermelho (iv) foi mantida permanentemente ligada.

Um gerador de sinal Advance também situado fora do insectário, foi usado para gerar tons de vôo artificiais. O sinal era enviado para um auxiliar de audição Zenith, agindo com o alto-falante, que projetava através de um suporte de madeira de pau-de-balsa em uma gaiola de mosquitos. A dimensão da cobertura era $2 \mathrm{~mm}$ de diâmetro, assim uma fonte pontual efetiva de som era produzida. A intensidade do som foi medida usando um mediador de nivel de som Dawe e filtro "band pass" associado. No sentido de reduzir o efeito de familiarização nos insetos, sons eram tocados por cinco segundos cada minuto, o sinal sendo controlado por um "timer" de 60 segundos, Quando os experimentos eram conduzidos sobre o rítmo de respostas em escuro constante um "timer" de sessenta segundos semelhante ligava o equipamento, com a exceção da fonte de infravermelho (iv), nos primeiros dez minutos em cada hora.

Uma resposta positiva ao sinal sonoro foi considerada ter ocorrido quando os machos voaram em direção ao alto-falante, passaram sobre o suporte de madeira de pau-de-balsa e tentaram copular com o alto-falante. Um máximo de dez machos podia ser discriminado a qualquer tempo de maneira que números de respostas maiores que este eram ainda contados como dez.
Experimentos preliminares indicaram que o número de respostas para um dado sinal sonoro depende da freqüência do sinal, da sua intensidade do tempo após o apagar da luz quando o sinal foi tocado. Assim, no sentido de encontrar a freqüência de resposta dos insetos, uma freqüência "controle" de $450 \mathrm{~Hz}$ era tocada em minutos alternados e cada outro minuto uma freqüência teste da mesma in. tensidade na emissão. O número médio de respostas pré e pós sinais teste foi calculado e considerado como $100 \%$ de resposta. Além disto a proporção relativa de respostas ao sinal teste foi determinado. Assim, se a média dos dois sinais controle era 8,5 e o número de respostas ao teste era 5 , então a resposta relativa era $59 \%$. As freqüências testes eram separadas em medidas de $50 \mathrm{~Hz}$ e após 20 tentativas com cada freqüência de 200 a $1000 \mathrm{~Hz}$ uma curva de resposta de freqüência era obtida. Este método tem a vantagem sobre o de Roth (1949), em que orientação para o pouso sobre a fonte sonora fora usada como critério de resposta mais do que as respostas de segurar e acoplar, e sobre a de Wishard \& Riordan (1959) em que os machos estavam disponiveis para mais de um teste e que a influência de qualquer mudança temporal na resposta era considerada.

No sentido de medir a amplitude de resposta dos machos a sons de diferentes intensidades, o suporte do alto-falante foi colocado no canto oposto da gaiola, em ângulo reto com a câmera. Os insetos em vôo eram visíveis contra uma grade de $25 \mathrm{~mm}$ quadrados (linhas brancas em papel preto) no fundo da gaiola. Quando o som era emitido, os insetos respondiam voltando-se e voando na direção dele. Usando a facilidade da reprise em baixa velo. cidade do gravador de vídeo-tape, a distância máxima de atração dos sons de diferentes intensidades e de fêmeas amarradas foi determinada.

As fêmeas foram amarradas na cabeça de um alfinete entomológico, usando-se tinta de cartaz de acrílico de secagem rápida. Isto deixava as asas e pernas da fêmea livres para se moverem e pareceu não impedir o comportamento de acasalamento normal. As fêmeas amarradas foram atadas em gaiolas-padrão contendo 50 machos. Usando-se o sis- 
tema de televisão, o comportamento de acasalamento que se segue ao apagar da luz foi estudado. Fotografias instantâneas da seqüência de acasalamento foram tiradas, usando-se o sistema de tv como um guia.

\section{Resultados}

A sequência de acasalamento entre machos maduros virgens e fêmeas está mostrada na figura 1. Os machos aproximavam-se das têmeas em vôo; voando verticalmente ul. trapassava-as (fig. 1a) e o par frontal de pernas do macho segura uma das pernas esticadas da fêmea. O macho então girava para uma posıçao ventre a ventre (fig. 1b) e, em menos de três segundos, as genıtálias do macho localizavam as da fêmea (fig. $1 c$ e d). Uma vez em contato genital, o macho solta as pernas da fêmea e adota uma posição, extremıdade a extremidade, (fig. 1d). Após meio minuto $(33 \pm 2$ segundos, média de 15 cópulas), os claspers do macho abrem e ele voa afastando-se. Durante o encontro inicial, a fêmea pára de voar mas retorna a voar uma vez que o contato genital é estabelecido. Assim, o par tenderia a cair de um enxame durante o contato inicial e não estava propenso a interferência intra específica de outros machos. Tal interferência tornou impossível para qualquer um macho manter o contato genital quan. do um grupo de machos era simultaneamente atraído para uma fêmea amarrada. Quando um par em cópula atraía outros machos, estes machos tentavam copular com o par. Tais machos adicionais tendiam a agarrar as asas do macho em cópula com seus claspers, dando origem em várias ocasiōes a fileira de três ou quatro machos cair um atracado ao outro.

A frequência de batimento de asa de adultos, "teneral", recentemente emergidos é de 100 a $200 \mathrm{~Hz}$ menor que de seus correlativos maduros (Clements. 1963; Roth, 1949). Dessa maneira machos recém-emergidos têm uma freqüência de batimento de asa semelhante à da fêmea madura e a fêmea recém-emergida tem "uma freqüência de batimento de asa que não é atrativa para os machos. Conseqüentemente, 15 machos recém-emergidos eram abordados por machos em vôo em que tentavam cópula com eles enquanto que fêmeas recém-emergidas não obtinham qualquer resposta dos machos.

Os machos também abordavam e tentavam acasalar-se com fêmeas amarradas do complexo Anopheles gambiae e Aedes aegyp$t i$, indicando que eles não eram capazes de distinguir entre seus próprios gêneros e outros gêneros.

A resposta à freqüência de $C$. quinquefasciatus macho está mostrada na fig. 2. Os machos respondem a sons na amplitude de 300 a $750 \mathrm{~Hz}$, com uma resposta máxima em $450 \mathrm{~Hz}$. Esta larga amplitude de resposta indica que o som do vôo da fêmea por "se" é improvável agir como um mecanismo isolante entre esta e outras espécies. A tabela 1 mostra a distância, na qual os machos foram atraidos por sons de diferentes intensidades e freqüências. Como seria esperado, os insetos respondem de uma maior distância a sons de intensidades maiores. A intensidade média produzida por dez fêmeas em vôo amarradas foi $37 \pm 2 \mathrm{~dB}$ a $50 \mathrm{~mm}$. A distância máxima de resposta a tais fêmeas amarradas e a sons de vôo artificais desta intensidade foi $50 \mathrm{~mm}$, indicando que entre os machos selvagens, somente serão capazes de perceber as fêmeas aqueles que estão numa distância de $50 \mathrm{~mm}$ delas.

TABELA 1

\begin{tabular}{c|c|c}
\hline $\begin{array}{c}\text { Freqüência } \\
(\mathrm{Hz})\end{array}$ & $\begin{array}{c}\text { Intensidade } \\
(\mathrm{dB})\end{array}$ & $\begin{array}{c}\text { Max. distância } \\
\text { de resposta (mm) }\end{array}$ \\
\hline \multirow{2}{*}{450} & 38 & 50 \\
& 45 & 125 \\
& 54 & 200 \\
& 55 & 250 \\
500 & 56 & 250 \\
& 40 & 50 \\
& 45 & 125 \\
600 & 54 & 175 \\
& 45 & 75 \\
& 54 & 200 \\
\hline
\end{tabular}

Fêmea amarrada 50 $37 \cdot b \pm 2$ 

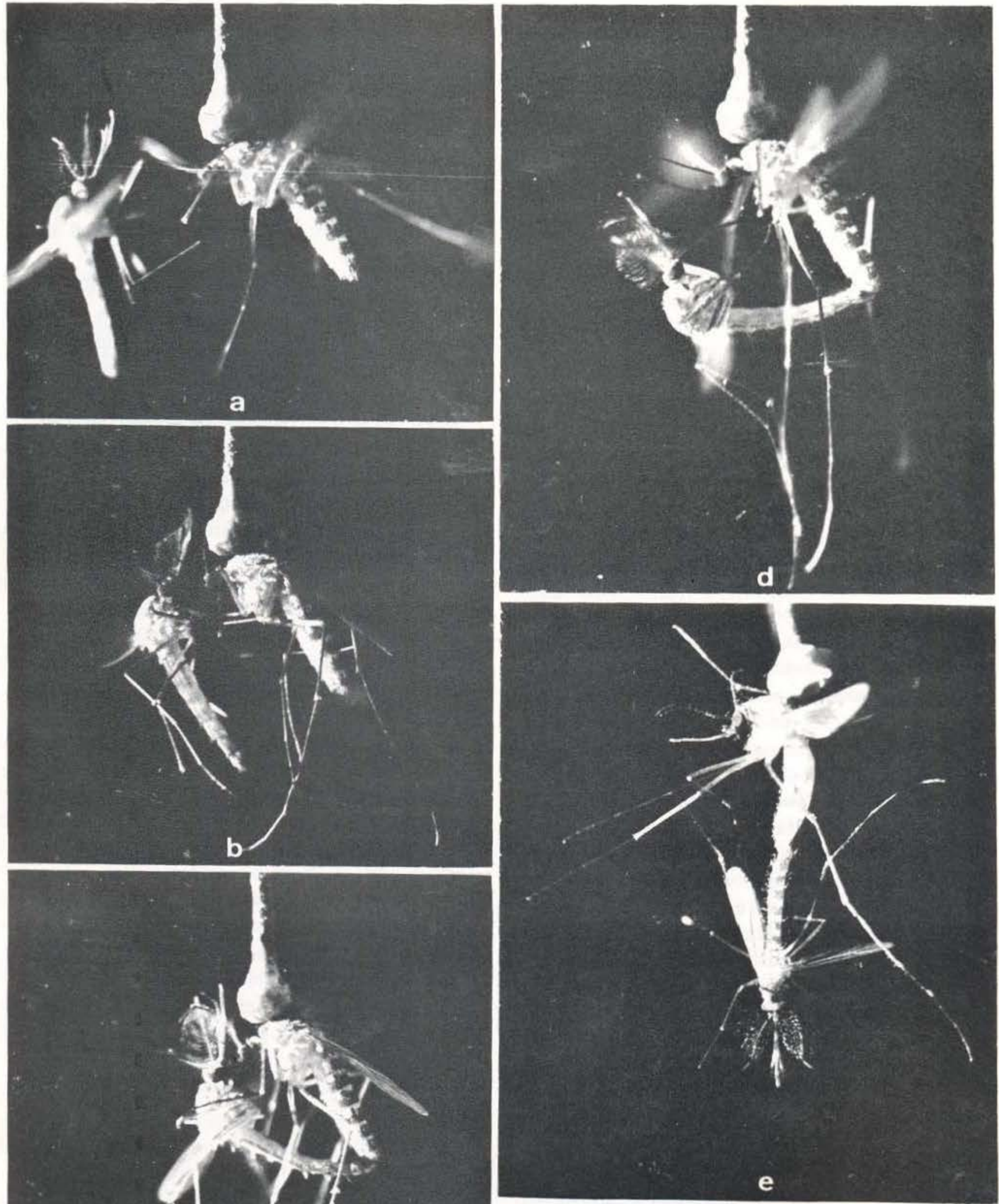

Fig. 1 - Sequêencia de acasalamento de Culex quinquefasciatus. Fotografia composta de linhagens do Brasil e África. 
Em dez ocasiões, tons de vôo artificiais foram emitidos para os machos quando fêmeas amarradas, com suas asas coladas foram colocadas bem em frente da abertura do alto-falante. Os machos responderam aos mesmos, pousando sobre a borda do alto-falante e pousando sobre a fêmea. Aqueles machos que desceram sobre a fêmea, contudo, não tentaram copular com ela.

A curva de resposta dos machos aos sons de vôo de fêmea $(450 \mathrm{~Hz}$ a $40 \mathrm{~dB})$ está mostrada na figura 3. O pico de resposta ocorreu 30 minutos depois de apagada a luz e nunca houve resposta ontes de a luz apagar. O número de machos respondendo ao som diminui após a primeira hora seguinte ao apagar da luz porém aumenta novamente quando se acende a luz (figura 4). Este padrão bimodal de resposta ao som continuou em escuro constante com picos de resposta ocorrendo aproximadamente cada dez horas.
As fibrilas na antena do macho de $C$. quinquefasciatus não mostram a ereção periódica apresentada pelas espécies de Anopheles (Charlwood, 1976; Charlwood \& Jones, 1979; Niphout, 1978). Assim, os machos estăo por todo tempo, fisicamente aptos a perceber o som de vôo da fêmea e durante a metade do período escuro quando nenhuma resposta foi dada, machos podiam ser ouvidos no monitor levantando vôo quando o sinal era emitido. Tais vôos induzidos eram de uma duração muito limitada e estes machos raramente pousavam sobre a borba do alto-falante.

Os enxames de machos de $C$. quinquefas. ciatus ocorrem em Manaus no entardecer e amanhecer. Os enxames ao entardecer, ocorrem em inúmeros locais sobre áreas de contrastes, usados para localização de enxames ("swarm markes") (Downes, 1958 e 1969). Os enxames do amanhecer mostraram menor número de indivíduos, săo restritos das áreas ao

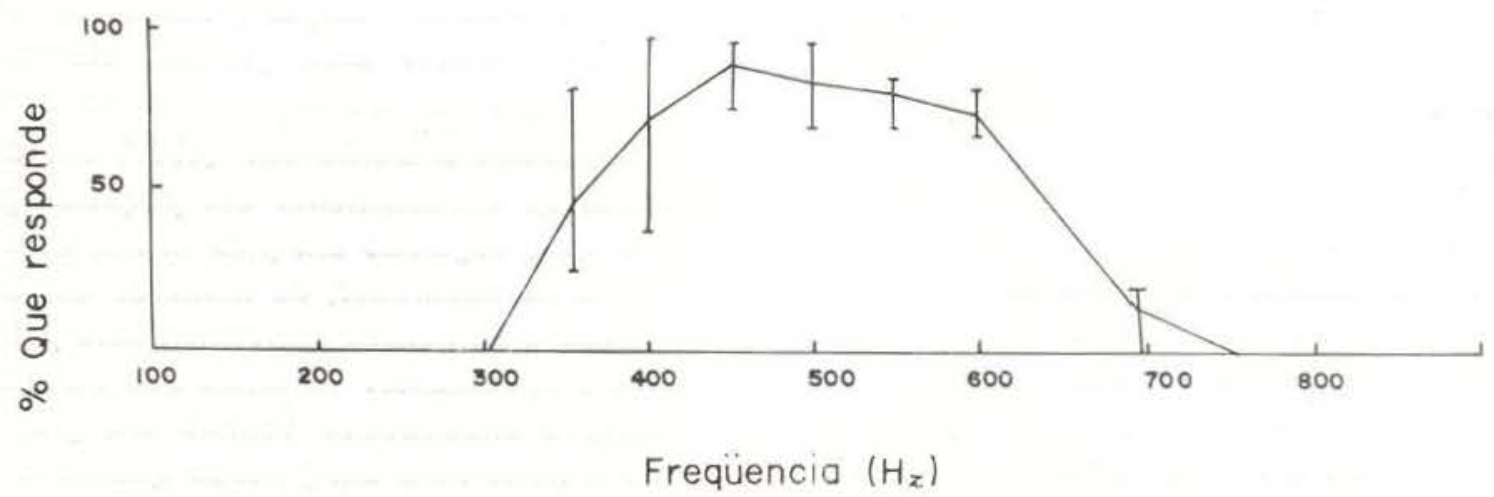

Fig. 2 - Curva de resposta da frequêencia da linhagem Keneba de C. quinquefasciatus sinais de $45 \mathrm{~dB}$ a $50 \mathrm{~mm}$ aa fonte de som. dB raiz média quadrada referente é $2.10^{-5} \mathrm{~N} / \mathrm{m}^{2}$.

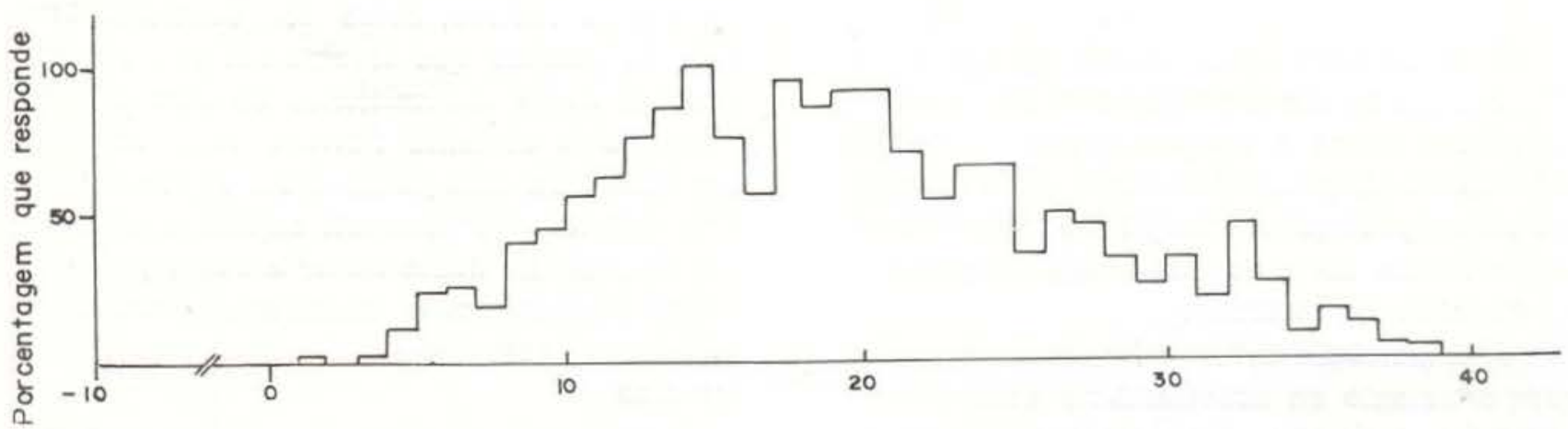

Minươ após a luz desligada

Fig. 3 - Resposta de macho de C. quinquefasciatus, linhagem Keneba, a sinais de $459 \mathrm{~Hz}$ em luz apagada. 


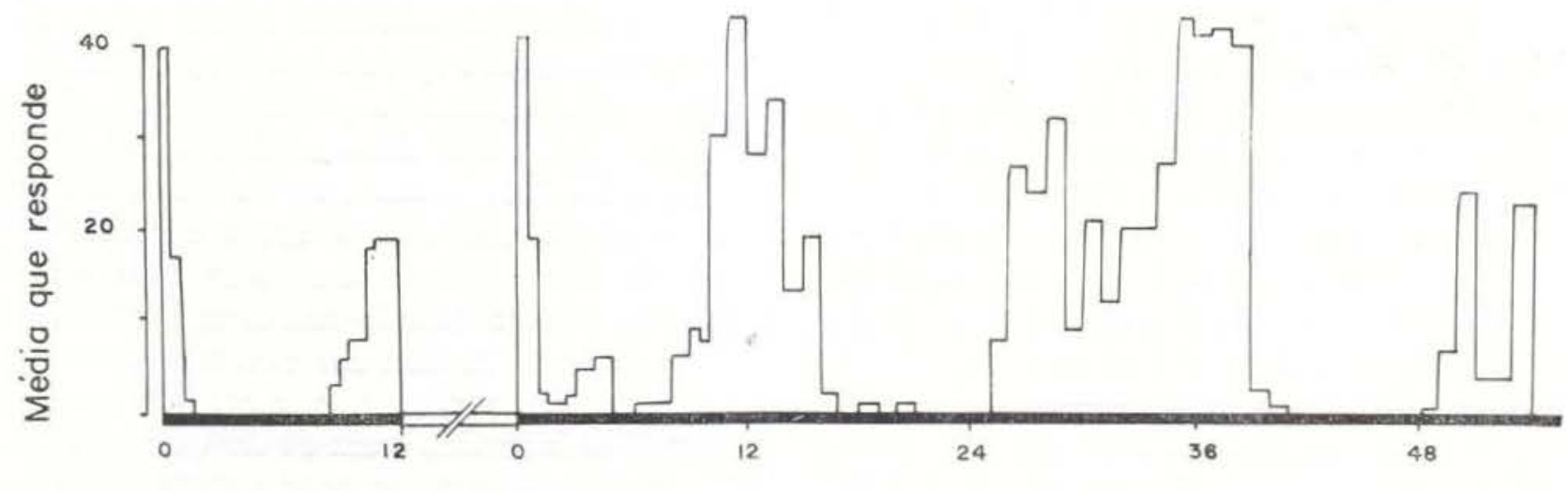

Horas

Fig. 4 - Resposta de machos a sinais de $450 \mathrm{~Hz}$ em escuro constante.

local de repouso dos machos. Durante uma série de observaçōes ao entardecer mas nunca ao amanhecer, mas dentro de um quarto, próximo ao armazém, onde os machos permaneciam em repouso durante à noite, os enxames foram observados em ambos os períodos. A atividade do enxame mostrou-se máxima, com uma mesma atividade luminosa, nos 2 períodos.

Os fatores como pressão atmosférica (Maw, 1962) e umidade também poderiam influenciar a atividade, e cruzamento foi observado das 01:00 às 02:00 horas, durante uma tempestade com descargas elétricas. Enxames ao entardecer e amanhecer foi também observado por Nielsen \& Nielsen (1962) em um estudo de laboratório do comportamento de vôo em grupo de $C$. quinquefasciatus.

\section{DISCUsSÃo}

Os resultados deste estudo ajudam a explicar algumas das discrepâncias de trabalhos anteriores sobre o comportamento de acasalamento de $C$. quinquefasciatus. Eles também indicam a possível estratégia adotada para assegurar altas taxas de inseminação específica de espécies na natureza.

Uma indicação definida foi obtida de que o comportamento de acasalamento está sob alguma forma de controle circadiano (figura 4) e dos resultadios é antecipado que o acasalamento estaria em pico no pôr do sol e no ama. nhecer. A resposta bimodal ao som pode ser interpretada como uma curva de resposta sinusoidal possivelmente equivalente a mudanças na excitabilidade central (Brady, 1975). Durante o claro, a resposta é inibida de maneira que, ao apagar da luz, está em um pico e mostra uma diminuição gradual. Antes do amanhecer existe uma gradual elevação na resposta que cessa abruptamente ao clarear.

Sebastian \& DeMeillon (1967) em experimentos de acasalamento em pequena gaiola, notou que, seguindo um pico inicial de acasa. lamento ao escurecer, os números de fêmeas fertilizadas aumentou uniformemente pela noite até 0 amanhecer. Machos não seriam normalmente encontrados voando em grupo durante a noite mas um período quando a atividade da fêmea está em um pico (Charlwood, 1976). Fatores como condições atmosféricas podem influenciar a atividade dos machos (Maw, 1962). Eles estão sempre aptos a responder às fêmeas, como foi concluído ante aqueles machos que levantaram vôo em resposta a sinais intermitentes de som de vôo, porém eles somente fizeram vôos de curta duração. Em uma gaiola cheia de fêmeas ativas, tais machos estariam sujeito a uma forma de estímulo muito maior e muito provavelmente localizariam e acasalariam com estas fêmeas que estariam em efeito de impulso sobre eles

Localização da fêmea pelos machos somente ocorre em uma curta distância; assim machos voando em grupo somente seriam capazes de perceber a fêmea se ele realmente 
voar para dentro do enxame. Uma vez localizadas, os machos parecem ser incapazes de cistinguir entre membros de suas próprias espécies e outras. Tais mecanismos discriminatórios como são dominados por Aedes aegypti (Nijhout \& Craig, 1971) não seriam necessários se os machos tivessem probabilidade de somente encontrar membros femininos de suas próprias espécies. Assim qualquer padrão de sistema de reconhecimento específico de espécie depende da escolha da fêmea, uma conclusão alcançada por Miles (1977) seguindo estudos de isoenzimas do complexo $C$. pipiens na Austrália.

A escolha feminina pode depender de enxame dos machos no tempo e local "correto" e na maneira "correta". Qualquer um destes tatores pode influenciar o comportamento da fêmea e todos eles aguardam pesquisa.

\section{AGRADECIMENTOS}

A maior parte deste trabalho ocorreu enquanto o autor recebia um financiamento do Medical Research Council da Gră-Bretanha. Gostaria de agradecer aos Drs. M. D. R. Jones e M. T. Gilles por suas ajudas e pelo uso das facilidades do Mosquito Behaviour Programme da Universidade de Sussex, durante o verão de 1978. As senhoritas C. S. Munck e S. J. Gubbins deram valiosa ajuda técnica.

\section{SUMMARY}

An investigation was conducted into the mating behaviour of strains of Culex quinquefasciatus Say from the Gambia, West Africa and Amazonas, Brazil. Usıng an infra-red sensitive television system for observation in the "dark"; experiments showed that males are attracted to the flight tone of the female and do not appear to discriminate between members of their own and other genera. The response of males to artificial female flight tones is at a peak in the hour following light off in an LD12:12 regime and shows a circadian pattern in constant dark. In the field mating was observed when the males were actively swarming at dusk and dawn. It is concluded that mating is dependant on male activity but that the choice of a species specific partner is dependant on the female.

\section{BIBLTOGRAFIA}

BRADY, J.

1975 - Circadian changes in central excitability the origin of behavioural rhythms in tsetse flies and other animals? J. Ent. (A) 50(2) 79-97.

CHARLwOOD, J.D.

1974 - Infra-red TV for watching mosquito behaviour in the "dark" Trans Roy Soc Trop Med Hyg 68264.

1976 - Observing mosquito behaviour in the dark using infra-red T.V. Trans Roy Soc Trop Med \& Hyg 70 280-281.

1979 - Studies on the biology and feeding habits of Culex quinquefasciatus Say from Manaus Amazonas Brasil. Acta Amazonica. No prelo.

Charlwoo4, J.D. \& Jones, M.D.R.

1979 - Mating behaviour in the mosquito Anopheles gambiae s.1. - I Close range and contact behaviour. Physiological Entomolo. gy In press.

Clements, A.N.

1963 - The physiology of mosquitoes. Pergamon Press.

DOWNES, J.A.

1958 - Assembly and mating in the biting Nematocera. Internl. Cong. Entomol. Proc. 10th Montreal (1959) 2: 425-434

1969 - The swarming and mating flights of Diptera. Ann. Rev. Ent. 14 271-298.

Galindo, $\mathrm{P}$.

1958 - Bionomies of Sabethes chloropterus Humboldt, a vectore of sylvan yellow fever in middle America. Amer. J. Trop. Med. Hyg. $7 \quad 429-440$.

MaW, M.G.

1962 - Some biological effects of atmospheric electricity Proc. Entomol. Soc. Ontario. 92 33-37.

MILES, S.J.

1977 - Assortative mating between Culex quinquefasciatus and C. molestus (Diptera, Culicidae) under simulated field conditions.

J. Aust. Ent. Soc. 16 389-392.

Nielsen, H.T. \& Nielsen, E.T.

1962 - Swarming of mosquitoes, laboratory experiments under controlled conditions. Ent. Exp. \& Appl. 54 14-32.2.

Nishout, H.F.

1978 - Control of antennal hair erection in male mosquitoes. Biol. Bull., 153 591-603. 
NiJhout, H.F. \& Craig, G.B.

1971 - Reproductive isoloation in Stegomyia mosquitoes. III Evidence for a sexual pheromone. Ent. Exp. \& Appl. 14 399-412.

Provost, D.W. \& Haeger, J.S.

1967 - Mating and pural attendance in Deinocerites cancer and comparasions with Opifex fuscus (Diptera, Culicidae) Ann. Ent. Soc. Amer. 60 565-574.

Ротн, L.M

1949 - A study of mosquito behaviour. An experimental Laboratory study of the sexual behaviour of Aedes aegypti (Linnaeus). Amer. Midland Nat. 40 262-352.
Sebastion, A. \& Demeillon, B.

1967 - Experiments on the mating of Culex pipiens fatigans in the laboratory. Bull. Wid. Hith. Org. 36 47-52.

Williams, F.M. \& Patternon, R.S.

1969 - Swarming and mating behaviour in Culex pipiens quinquefasciatus. Mosquito Nens 29 662-666.

WisBart, G. \& RIORDAN, D.F.

1959 - Flight responses to various sounds by adult males of Aedes aegypti (Linnaeus) Can. Entomologist. 91 181-191.

(Aceito para publicação em 17/04/79) 